\title{
34. SOME PALEOMAGNETIC RESULTS FROM DEEP SEA DRILLING PROJECT LEG 67 OFF GUATEMALA ${ }^{1}$
}

\author{
Wulf Achim Gose, Institute for Geophysics, University of Texas at Austin, Austin, Texas
}

\begin{abstract}
The basalts and overlying lower Miocene chalks from the Cocos Plate reference Site 495 are magnetically extremely stable and yield latitudes of $3.8^{\circ} \pm 2.3^{\circ}$ for the basalts and $3.2^{\circ} \pm 2.3^{\circ}$ for the sediments. Because the polarity of magnetization cannot be determined, the latitudes can be either north or south. Three Late Cretaceous and one Oligocene sample from Site 494 on the lower slope have inclinations that imply that these rocks formed near or slightly north of their present latitude.
\end{abstract}

\section{INTRODUCTION}

The objective of the paleomagnetic study of samples recovered on DSDP Leg 67 off Guatemala was to obtain information relevant to the motion of the Cocos Plate and possibly to aid in the interpretation of the depositional history of the sediments in a convergent margin. Because of disturbed cores or similar considerations that would destroy the paleomagnetic record, sampling was unsystematic and limited. The majority of samples (55) are from Site 495, the Cocos Plate reference site. The remaining samples are distributed as follows: 16 samples from Site 499 on the trench floor; 9 samples from Site 500 also on the trench floor but at the base of the landward slope; 4 samples from the deepest part of Site 494 on the trench lower slope (see Table 1 for a list of samples used in this study).

\section{METHOD}

The magnetic properties were measured in the Galveston Laboratory of the University of Texas Institute for Geophysics using a cryogenic magnetometer. Prior to and during the experimental procedures, the samples were kept in a magnetically shielded room with an ambient field of about 100 gammas. Inside the magnetometer, as well as around the alternating field (AF) demagnetization coil, the field was less than 2 gammas.

\section{RESULTS}

The intensity of magnetization of the samples ranges over 6 orders of magnitude. Most samples proved to be extremely stable against AF-demagnetization in intensity as well as direction. In particular, no sample carried a soft magnetization, i.e., a magnetization that is removed by demagnetization in a few tens of oersteds (Fig. 1). Such a soft magnetization is often a viscous magnetization resulting from exposure to magnetic fields during coring and sample preparation (compare the effect on lunar samples, e.g., Pearce et al., 1973). I have not yet carried out specific tests but consider it likely that the storage of the samples in a low magnetic field for two weeks to six months prior to measuring successfully removed any viscous magnetization.

\footnotetext{
${ }^{1}$ Aubouin, J., von Huene, R., et al., Init. Repts. DSDP, 67: Washington (U.S. Govt. Printing Office).
}

\section{Cocos Plate Reference Site $\mathbf{4 9 5}$}

Plate tectonic considerations (e.g., Hey, 1977) suggest that the crust of the Cocos Plate originated near the equator. Thus the magnetic inclination of the basalts and basal sediments should have a value near zero. To distinguish between positive and negative inclination requires, therefore, extremely accurate sample orientation. For basalts it is also necessary to analyze several samples in order to average out the effects of secular variation. Figure 2 shows the change in intensity and inclination during AF demagnetization to 600 Oe for the basalt samples and some chalk samples from Site 495 . Because the samples are extremely stable and come from the least-disturbed cores, it seems reasonable to use the scatter in inclination as a measure of accuracy. An error of $\pm 10^{\circ}$ is indicated.

Figure 3 depicts the magnetic inclination as a function of depth for Site 495. The samples in the depth interval 20 to 45 meters are olive gray hemipelagic mud. Although the samples are individually quite stable, the inclinations among the samples scatter badly. This is most likely the result of drilling disturbances, and these data will be deleted from further discussion.

Below a sub-bottom depth of $\mathbf{4 2 8 . 6}$ meters the coring recovered basalt. The 11 samples were extremely stable against AF demagnetization to $600 \mathrm{Oe}$ (Fig. 2). The mean inclination after demagnetization to $200 \mathrm{Oe}$ is $-7.2^{\circ}$ with a standard deviation of $4.5^{\circ}$, compared with a value of $-7.7^{\circ} \pm 4.5^{\circ}$ after 600 Oe demagnetization.

The basalts are overlain by lower Miocene chalk and ooze (178.0-428.5 m). Out of 27 samples five were unstable. All stable inclinations are shallow $\left(|I|<15^{\circ}\right)$, implying deposition near the equator. Positive as well as negative inclinations are observed, but the sampling density as well as the uncertainty in sample orientation are insufficient to establish a reversal stratigraphy. The deepest sedimentary sample has the same inclination as the underlying basalts and will be included statistically with the basalts. The mean inclination of the remaining samples $(N=21)$ is $|I|=6.4^{\circ} \pm 4.6$ after 200 Oe demagnetization. The lower Miocene chalks accumulated during some 7 or 8 m.y. During this time span the Cocos Plate moved approximately $5^{\circ}$ or so to the north, re- 
Table 1. List of samples used in this study.

\begin{tabular}{|c|c|c|c|}
\hline $\begin{array}{c}\text { Sample } \\
\text { (hole-core-section) }\end{array}$ & $\begin{array}{l}\text { Sub-bottom } \\
\text { Depth }(\mathrm{m})\end{array}$ & $\begin{array}{c}\text { Sample } \\
\text { (hole-core-section) }\end{array}$ & $\begin{array}{l}\text { Sub-bottom } \\
\text { Depth (m) }\end{array}$ \\
\hline Hole 494A & & Hole 495 (cont.) & \\
\hline $22-2$ & 239.66 & $45-5$ & 424.82 \\
\hline $29-1$ & 304.27 & $46-1$ & 427.70 \\
\hline $29-1$ & 304.29 & $46-1$ & 428.70 \\
\hline $30-1$ & 313.68 & $47-1$ & 429.41 \\
\hline & & $48-1$ & 436.63 \\
\hline Hole 495 & & $48-2$ & 438.29 \\
\hline $3-1$ & 20.10 & $48-2$ & 439.02 \\
\hline $3-2$ & $\begin{array}{l}20.10 \\
21.01\end{array}$ & $48-2$ & 439.21 \\
\hline $3-3$ & 22.36 & $48-2$ & 439.30 \\
\hline 3-3 & 23.28 & $48-3$ & 439.80 \\
\hline $3-4$ & 24.51 & $48-3$ & 440.54 \\
\hline $3-5$ & 25.51 & $48-4$ & 441.73 \\
\hline $4-1$ & 29.51 & $49-1$ & 446.11 \\
\hline $4-2$ & 31.01 & Hole 499 & \\
\hline 4-3 & 32.40 & Hole 499 & \\
\hline $4-4$ & 33.40 & $3-4$ & 15.41 \\
\hline $4-5$ & 34.40 & $6-3$ & 43.22 \\
\hline $5-1$ & 39.01 & $7-3$ & 52.29 \\
\hline $5-2$ & 40.51 & $7-4$ & 54.14 \\
\hline $5-3$ & 42.01 & $10-5$ & 83.87 \\
\hline $5-4$ & 43.01 & $11-3$ & 90.22 \\
\hline $22-5$ & 205.68 & $12-3$ & 103.03 \\
\hline $24-7$ & 219.06 & $13-7$ & 115.47 \\
\hline $26-6$ & 246.08 & $14-3$ & 118.07 \\
\hline $28-6$ & 264.08 & & \\
\hline $31-6$ & 293.85 & Hole 499 & \\
\hline $33-2$ & 306.89 & $15-2$ & 126.96 \\
\hline $33-6$ & 311.68 & $\begin{array}{l}13-2 \\
18-6\end{array}$ & 160.80 \\
\hline $34-5$ & 319.75 & $19-1$ & 163.47 \\
\hline $35-4$ & 328.22 & $22-1$ & 191.71 \\
\hline $36-4$ & 337.88 & & \\
\hline $\begin{array}{l}37-4 \\
38-4\end{array}$ & $\begin{array}{l}347.48 \\
356.90\end{array}$ & Hole 499D & \\
\hline $39-4$ & 366.53 & $1-1$ & Wash core \\
\hline $41-2$ & 381.92 & $1-1$ & Wash core \\
\hline $41-6$ & 387.15 & $1-1$ & Wash core \\
\hline $42-3$ & 393.54 & & \\
\hline $42-5$ & 395.78 & Hole 500 & \\
\hline $43-3$ & 402.98 & $4-2$ & 25.46 \\
\hline $43-5$ & 405.23 & $\begin{array}{l}4-2 \\
7-6\end{array}$ & $\begin{array}{l}20.40 \\
59.96\end{array}$ \\
\hline $43-5$ & 405.28 & $\begin{array}{l}7-6 \\
7-7\end{array}$ & 61.80 \\
\hline 43-6 & 406.91 & $9-4$ & 76.47 \\
\hline $\begin{array}{l}44-2 \\
44-3\end{array}$ & $\begin{array}{l}411.32 \\
412.47\end{array}$ & $9-6$ & 78.74 \\
\hline $\begin{array}{l}44-3 \\
44-4\end{array}$ & $\begin{array}{l}412.47 \\
413.09\end{array}$ & $9-6$ & 79.33 \\
\hline $44-5$ & 415.17 & $9-7$ & 80.58 \\
\hline $44-6$ & 416.86 & $18-1$ & 157.00 \\
\hline $45-4$ & 423.89 & $19-1$ & 158.72 \\
\hline
\end{tabular}

sulting in a $10^{\circ}$ change in inclination. With the available data, such a small change cannot be detected; and no information about an origin north or south of the equator can be inferred on the basis of latitude changes. The data in the sub-bottom depth range from 430 to 400 meters (Fig. 3) are suggestive of a gradual change from negative to positive inclinations. Because a southward motion of the Cocos Plate can be ruled out, the trend implies a northward motion across the equator. In this case, the basalts were extruded and the first chalky sediments were deposited at $3.8^{\circ} \mathrm{S} \pm 2.3^{\circ}$ during a time of normal magnetic polarity, and the change to positive inclinations in the overlying chalks reflects the northward motion of the newly created crust to $3.2^{\circ} \mathrm{N} \pm 2.3^{\circ}$. The problem with this interpretation is that it requires an
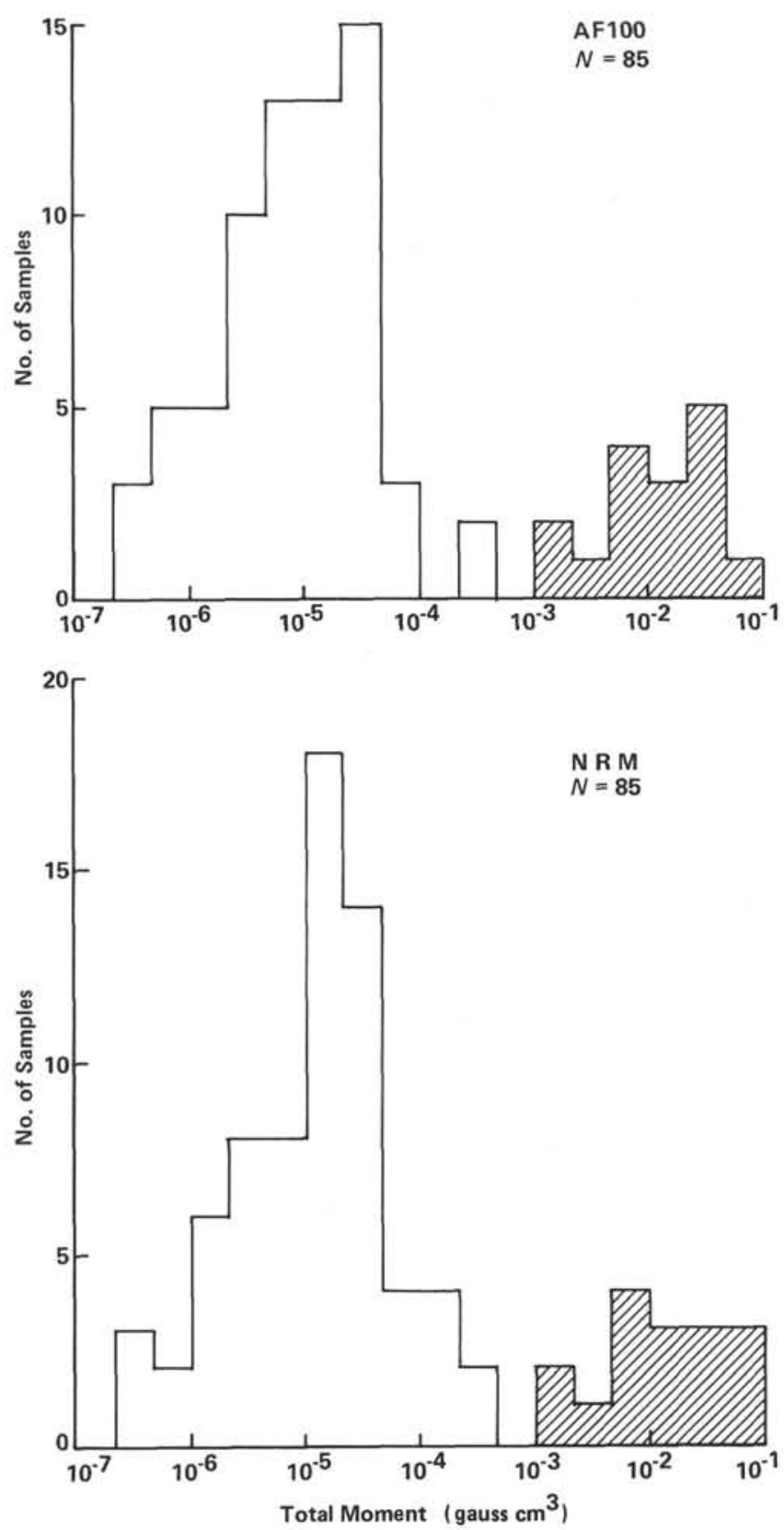

Figure 1. Comparison of intensity of natural remanent magnetization (NRM) with intensity after demagnetization to 100 Oe (AF100) for all basalt samples (shaded) and all sedimentary samples. (To convert the total moment to specific intensity [gauss] the values must be divided by about 10.)

unreasonably fast spreading rate. On the basis of magnetic anomaly and bathymetric data, Hey (1977) places the early Cocos-Nazca spreading center a few degrees south of the equator. This is supported by the stratigraphic succession of Site 495, which records the northward passage of the Cocos Plate through the equatorial belt of high productivity. The paleomagnetic data are compatible with these results but do not provide independent evidence.

\section{Site 499-Trench Floor}

We analyzed 13 sedimentary samples from Hole 499 and 3 basalt samples from Hole 499D (which we later 

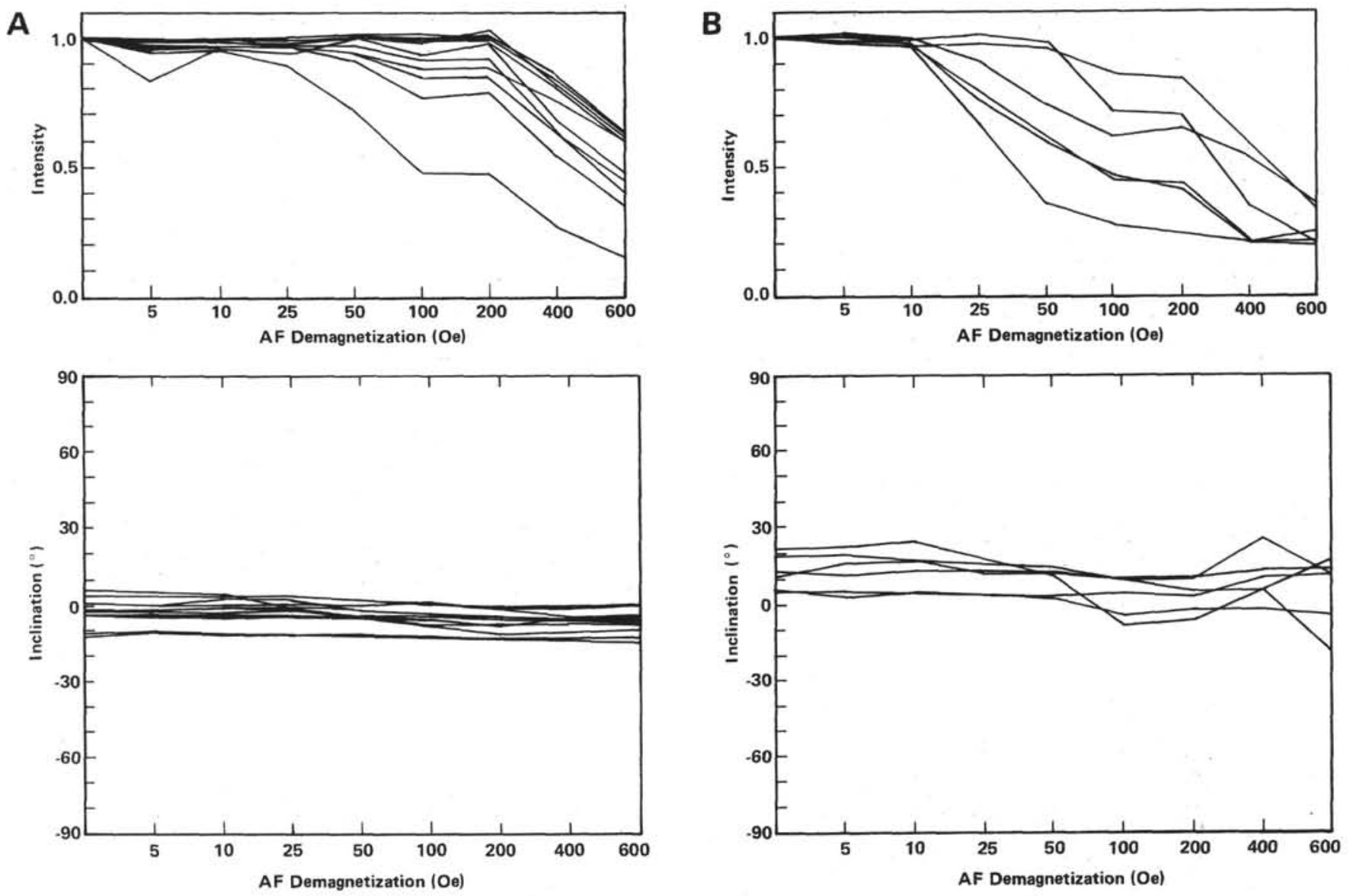

Figure 2. Normalized intensity and inclination as a function of demagnetizing field. A. Basalts from Site 495 . B. Chalks from Site 495 .

learned were unoriented). All but one sample are stable against AF demagnetization (Fig. 4). However, the scatter in the data precludes a meaningful interpretation. The scatter is probably the result of drilling disturbances (see the core descriptions in the Site 499 report).

\section{Site 500-Base of Landward Slope}

The results from Site 500 are very similar to those from Site 499. Only one sample out of nine was magnetically unstable. According to the initial core description all seven sedimentary samples are from turbidites, and the cores show drilling disturbances. It is, therefore, not surprising that the magnetic data are incoherent (Fig. 5), The two basalt samples are from Core 18, Piece 7 , and Core 19, Piece 3, both of which are oriented. The inclination values of $+27^{\circ}$ and $-23^{\circ}$ probably imply that the pieces represent loose rubble rather than bedrock.

\section{Site 494-Lower Slope}

The recovery of Upper Cretaceous sediments on the slope was quite unexpected. The critical question is whether these sediments formed in the open ocean and were accreted or whether they originated near their present position and were incorporated into the slope sediments by slumping (von Huene, Aubouin, et al., 1980). Four samples were carefully selected by R. von Huene and $\mathrm{J}$. Ladd to test whether a paleomagnetic analysis could place constraints on their original latitude. Sam- ples 1 and 2 (304.27 $\mathrm{m}$ and $304.29 \mathrm{~m}$ sub-bottom depth) are Upper Cretaceous mudstones. Sample 3 is an Upper Cretaceous limestone clast $(313.68 \mathrm{~m})$, and Sample 4 is an Oligocene limestone clast $(239.66 \mathrm{~m})$. Sample 4 was cut into two pieces ( $4 \mathrm{a}$ and $4 \mathrm{~b})$. The clast was selected because a bedding plane could be recognized, and the remanent magnetization was measured relative to this plane. The fractured nature of the rock and the shape and size of the clasts made the exact orientation of the samples difficult.

The samples were demagnetized to 200 Oe (Fig. 6). The three Cretaceous samples yield latitudes of $17^{\circ}$, $21^{\circ}$, and $28^{\circ}$, and the Oligocene samples $(4 \mathrm{a}, 4 \mathrm{~b})$ give values of $7^{\circ}$ and $12^{\circ}$. The error in these values due to orientation difficulties is about $\pm 5^{\circ}$ judging from the inclination difference between Samples $4 \mathrm{a}$ and $4 \mathrm{~b}$. Despite this error, the results strongly suggest that the samples formed near their present latitude (i.e., $12.7^{\circ} \mathrm{N}$ ) or a short distance farther north.

\section{Summary}

The paleomagnetic data from the Cocos Plate reference site attest to a near-equatorial origin of the basalts and basal sediments, in agreement with the predicted plate motion. The northward motion of the Cocos Plate is also recorded in Late Cretaceous and Eocene sedimentary rocks from the Pacific Coast of southern Nicaragua and Costa Rica (Gose, 1980). 


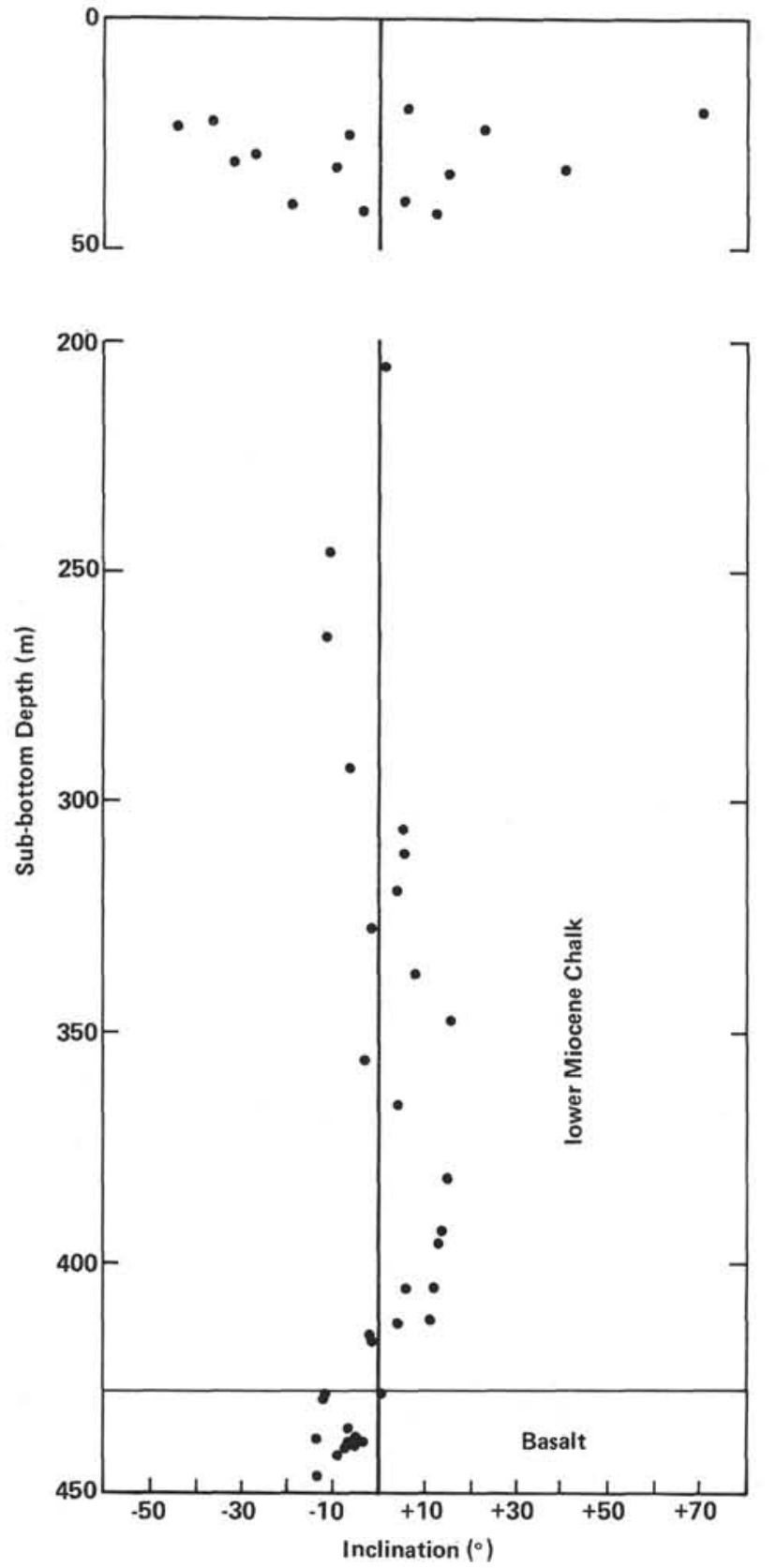

Figure 3. Inclination versus depth for Site 495 samples.

The analysis of samples from Sites 499 and 500 did not yield significant results. The great scatter in inclination probably reflects drilling disturbances.

Three Late Cretaceous and one Oligocene sample from Site 494 on the slope have inclinations that imply that the rocks formed near or north of their present latitude. In evaluating the significance of these samples it is important to realize the rather different tectonic setting of this area during the Late Cretaceous to early Tertiary. The Cocos-Nazca spreading center came into existence only about $25 \mathrm{Ma}$ (Hey, 1977). Honduras, after undergoing large rotations throughout the Cretaceous, sutured onto Guatemala along the Motagua Fault about $70 \mathrm{Ma}$ (Gose and Swartz, 1977; Gose et al., 1980; Sutter, 1979; Lawrence, 1976). It thus seems extremely dif-
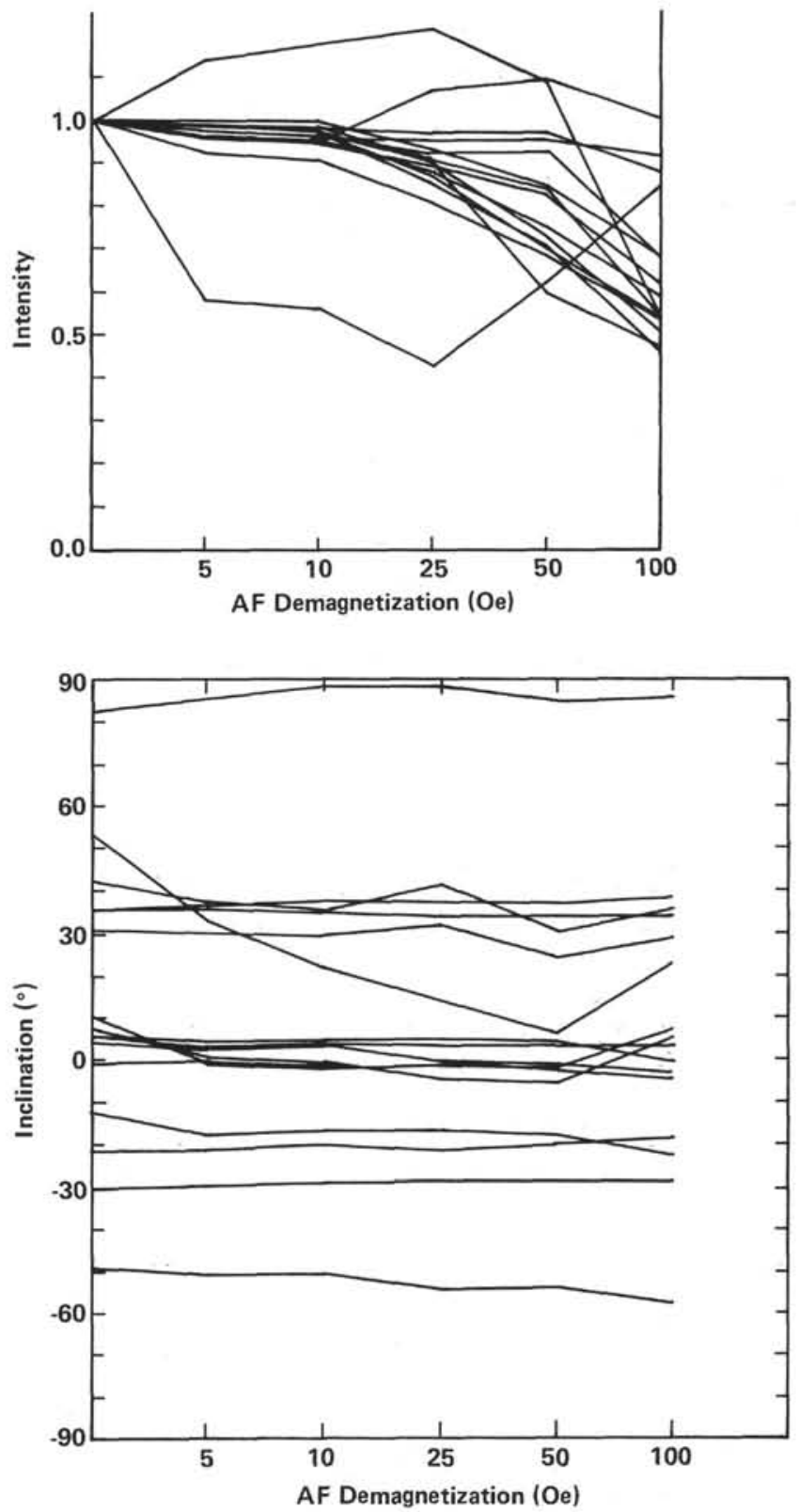

Figure 4. Normalized intensity and inclination as a function of demagnetizing field for Site 499 samples.

ficult to determine the source area of the old rocks at Site 494. An origin on the Farallon Plate and subsequent easterly drift seems as likely as a near-shore formation and later incorporation into the slope sediments.

\section{ACKNOWLEDGMENTS}

I wish to thank Drs. John Ladd and Roland von Huene for selecting the samples for me and for informing me about the initial results of Leg 67. This work was supported by research grants from Chevron Overseas Petroleum Incorporated, Gulf Oil Exploration and Production Company, and Texaco Incorporated, and the University of Texas. It constitutes University of Texas Institute for Geophysics Contribution Number 470 .

\section{REFERENCES}

Gose, W. A., 1980. Evidence for a tectonic discontinuity in Nicaragua. Trans. Am. Geophys. Union, 61:946. (Abstract) 
Gose, W. A., Scott, G. R., and Swartz, D. K., 1980. The aggregation of Mesoamerica: paleomagnetic evidence. In Pilger, R. H. (Ed.), The Origin of the Gulf of Mexico and the Early Opening of the Central North Atlantic Ocean: Baton Rouge (Louisiana State University Press), pp. 51-54.

Gose, W. A., and Swartz, D. K., 1977. Paleomagnetic results from Cretaceous sediments in Honduras: tectonic implications. Geology, 5:505-508.

Hey, R., 1977. Tectonic evolution of the Cocos-Nazca spreading center. Geol. Soc. Am. Bull., 88:1404-1420.

Lawrence, D. P., 1976. Tectonic implications of the geochemistry and petrology of the El Tambor Formation: probable oceanic crust in Central Guatemala. Abs. Geol. Soc Am., p. 973. (Abstract)
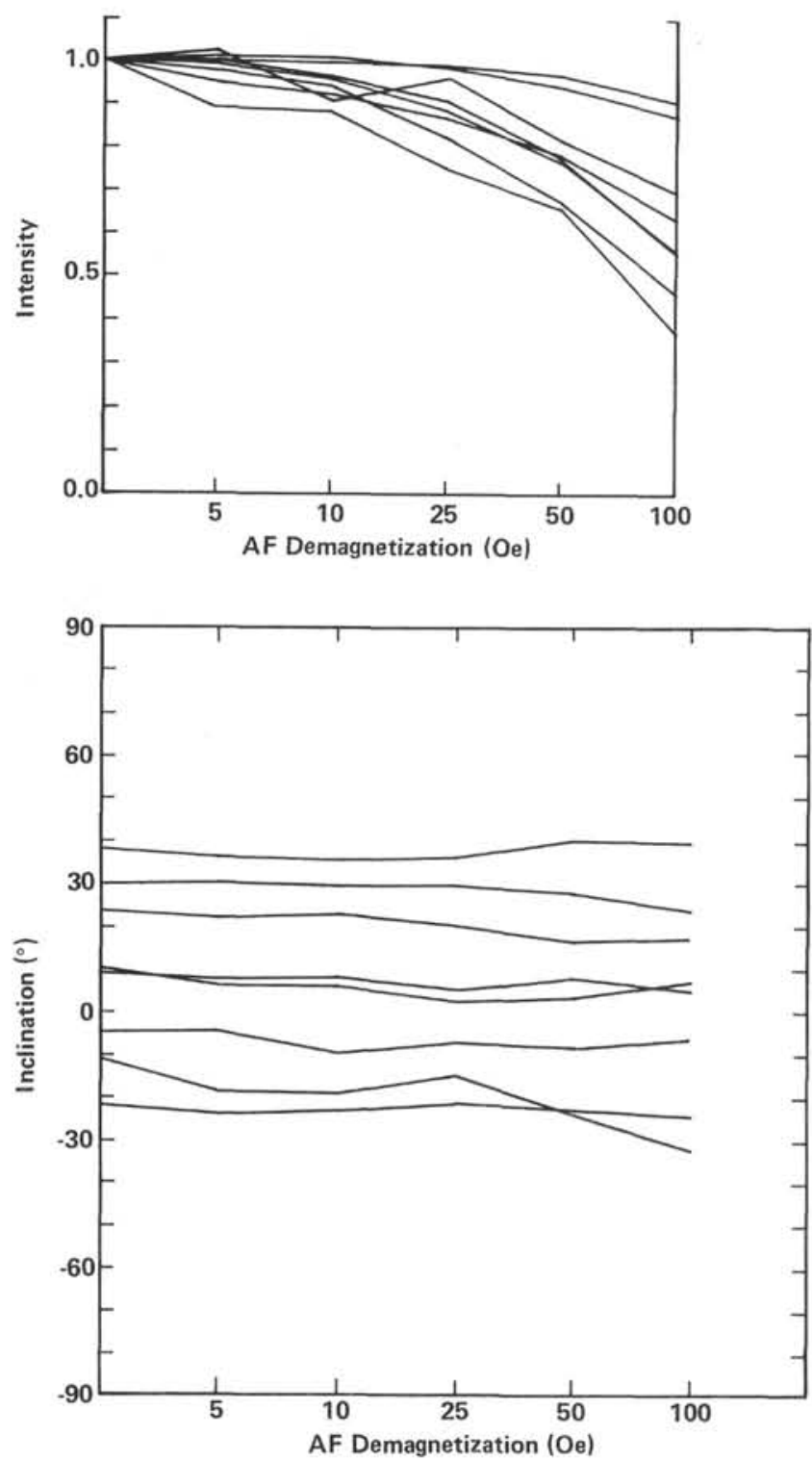

Figure 5. Normalized intensity and inclination as a function of demagnetizing field for Site 500 samples.
Pearce, G. W., Gose, W. A., and Strangway, D. W., 1973. Magnetic studies of Apollo 15 and 16 lunar samples. Proc. Fourth Lunar Sci. Conf., 3:3045-3076.

Sutter, J. F., 1979. Late Cretaceous collision tectonics along the Motagua fault zone, Guatemala. Abs. Geol. Soc. Am., p. 525. (Abstract)

von Huene, R., Aubouin J., Azéma, J., Blackinton, G., Carter, J. A., Coulbourn, W. T., Cowan, D. S., Curiale, J. A., Dengo, C. A., Faas, R. W., Harrison, W., Hesse, R., Hussong, D. M., Ladd, J. W., Muzylöv, N., Shiki, T., Thompson, P. R., and Westberg, J., 1980. Leg 67: the Deep Sea Drilling Project Mid-America Trench Transect off Guatemala. Geol. Soc. Am. Bull., 91:421-432.
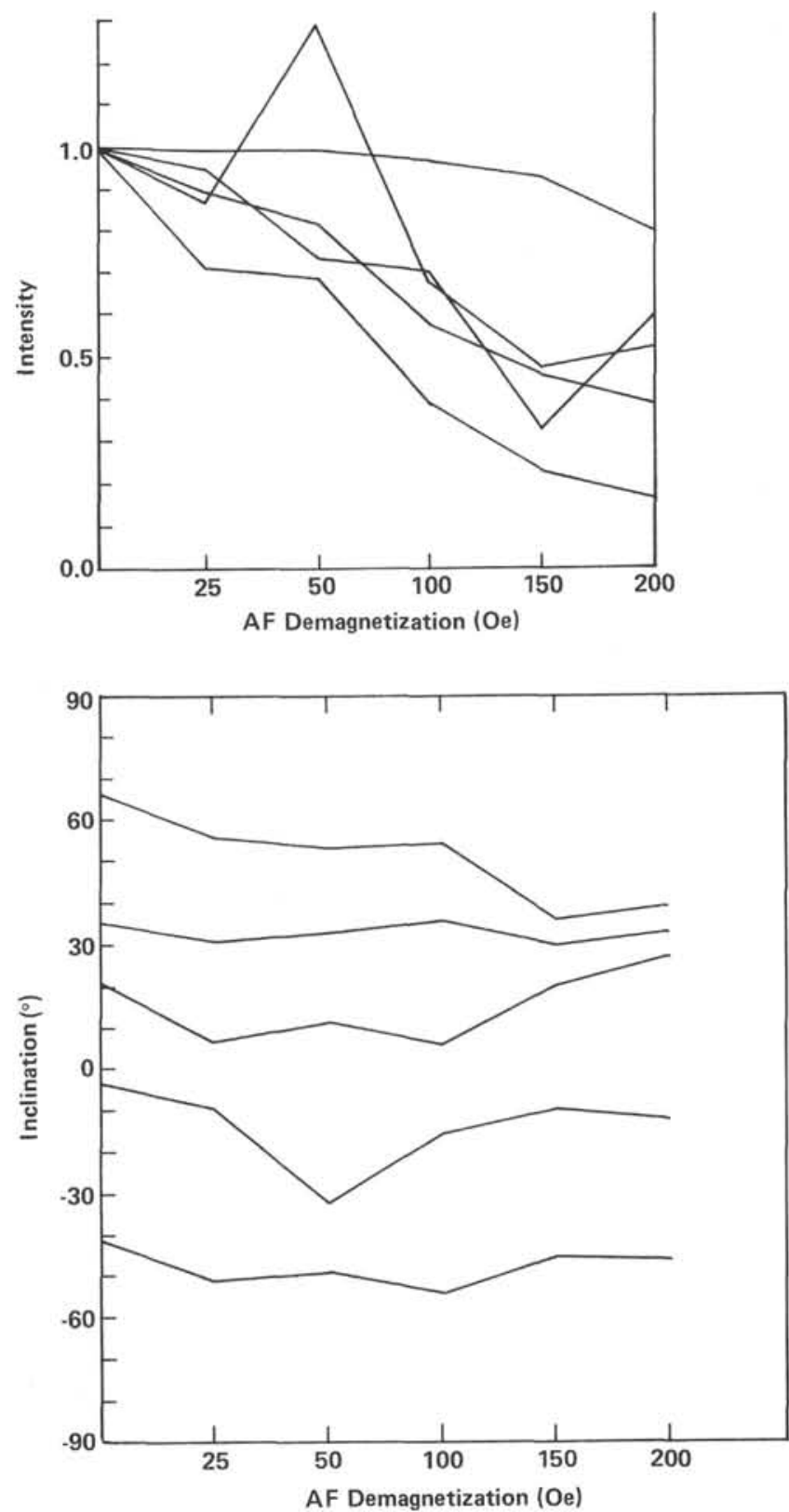

Figure 6. Normalized intensity and inclination as a function of demagnetizing field for Site 494 samples. 